\title{
Structural Stability of Nano-Crystalline Aluminum-Glass Composites
}

\author{
${ }^{1}$ O.W. Abodunrin and ${ }^{2}$ S.S. Oluyamo \\ ${ }^{I}$ Department of Physics, Joseph Ayo Babalola University, Osun State, Nigeria. \\ ${ }^{2}$ Condensed Matter Section, Department of physics, Federal University of Technology, Akure, Ondo state,
} Nigeria.

\begin{abstract}
Effects of particle size of the material in nanometer on solid state, structural properties AluminumGlass based samples are reported in this study. The particle size of $25 \mu \mathrm{m}$ was used for both Aluminum and Glass powders respectively. The samples were prepared in powdered form of various Al-Glass proportions. The weight of Aluminum ranges between 20 - 60 percent in the composites. Results showed from X-ray diffraction analyses that Aluminum addition and the determined particle size greatly influence the structural stability of the samples. It was revealed that samples were structurally stable in the range of Aluminum composition and the observed size of crystals, measured Width at Middle of Maximum Height and structural parameters were found in nanometers. The Al-Glass materials were noted to crystallize with FCC and BCC lattice structures.
\end{abstract}

Keywords: Particle size, composition, structural stability, solid state properties, structural parameters, toughness, ductility and strength.

\section{Introduction}

Structural stability is the ability of a body or system to return to a previously established steady stabled structure after being perturbed. In other words, structural stability is the ability of a system to regain balance at the moment of giving it any perturbation ${ }^{1}$. Structural stability of a material could also imply the same structural parameters and close solid state properties irrespective of the particle size and metallic composition of the constituent materials ${ }^{2,3,4}$. Structural stability is a property which is usually measured in relation to measured Width at Middle of Maximum Height (WMMH) of the peak of count of X-rays and size of crystals. Structural stability is associated with composites and it was determined from observation of the structural parameters (two theta values, lattice constant, miller indices and d-spacing) of a material.

The choice of Aluminum is as a result of its ductility and strength used in most construction works. Glass has low ductility and the need for reinforcement of a material of high ductility is considered ${ }^{5}$. Therefore, Aluminum-Glass composites were proposed for industrial and domestic purposes. In most metallurgical work Aluminum is considered one of the best candidates to be incorporated in Glass structure because of its toughness and its structural stability in composites ${ }^{6}$.Therefore, attention in this study is geared towards determining the structural stability Al-Glass materials at same particle sizes.

\section{Experimental Procedure}

The materials used for the study include Aluminum powder of purity of $95.5 \%$ purity and of particle size of $25 \mu \mathrm{m}$ obtained from British drug House (BDH), England. Glass powder of particle size $25 \mu \mathrm{m}$ which had earlier been crushed and pulverized before sieving with a mesh of appropriate size at mechanical section of Centre for Energy Research and Development (CERD), Obafemi Awolowo University, Ile-Ife, Nigeria was used. Weighing was done with digital weighing balance (Model, BT 200) of sensitivity 0.001g. Formula for mixing in percentage is $\mathrm{Al}_{\mathrm{x}} \mathrm{Glass}_{100-\mathrm{x}} \mathrm{x}=20.0,30.0,40.0$ and 60.0. The Aluminum and Glass powders in grams were mixed together in 4 different ratios. The mixing was carried out manually in a closed container. Powdered samples were presented at Engineering Material Development Institute (EMDI), Akure, Nigeria, for X-ray diffraction analyses.

\subsection{Formulation}

Spacing (d) between atomic layers is obtained and it is given as ${ }^{7}$

$$
d=\frac{\lambda}{2 \sin \alpha}
$$

Size of crystals of sample was calculated and it is obtained from this formula ${ }^{8}$

$$
\text { Size of crystals }=\frac{k \lambda}{\cos \alpha(W M M H)}
$$


$\mathrm{K}=0.9$ and $\lambda$ is the wavelength of the radiation from copper $(0.1054 \mathrm{~nm})$ which passes through the crystals while the WMMH is the measured Width at Middle of Maximum Height and $\alpha$ is angle between surface of the sample and the incident ray.

Miller indices $(\mathrm{a} b \mathrm{c})$ was determined by using this formula ${ }^{8}$

$$
\begin{aligned}
& \sum\left(a^{2}+b^{2}+c^{2}\right)=1000 / 60.547 \mathrm{~d}^{2} \\
& e=d \sqrt{\left(a^{2}+b^{2}+c^{2}\right)}
\end{aligned}
$$

where $\mathrm{e}$ is the lattice constant.

The miller indices ( $\mathrm{a} b \mathrm{c}$ ) could be obtained from equation (3). Once the $\mathrm{d}$ spacing is determined from $\mathrm{X}$ ray diffraction analysis, it is substituted in the Right Hand Side (R.H.S) of equation (3) and the value obtained is divided into three segments such that the addition of the square of each sub-segment of the three segments give the value obtained on the (R.H.S) of equation (3). From this the miller indices is determined.

III. Results

\begin{tabular}{|c|c|c|c|c|}
\hline Samples & $2 \alpha{\left({ }^{0}\right)}^{\prime}$ & d $\left(\mathbf{A}^{\mathbf{0}}\right)$ & $\mathbf{a} \mathbf{b} \mathbf{c}$ & e(nm) \\
\hline \multirow{3}{*}{$\mathbf{A l}_{20}$ Glass $_{80}$} & 38.589 & 2.331 & 111 & 0.4037 \\
\hline & 44.846 & 2.019 & 200 & 0.4038 \\
\hline & 65.178 & 1.430 & 220 & 0.4045 \\
\hline \multirow{3}{*}{$\mathbf{A l}_{30}$ Glass $_{70}$} & 38.544 & 2.333 & 111 & 0.4041 \\
\hline & 44.804 & 2.021 & 200 & 0.4042 \\
\hline & 65.154 & 1.431 & 220 & 0.4047 \\
\hline \multirow[t]{3}{*}{$\mathbf{A l}_{40}$ Glass $_{60}$} & 38.691 & 2.325 & 111 & 0.4027 \\
\hline & 44.946 & 2.015 & 200 & 0.4030 \\
\hline & 65.275 & 1.428 & 220 & 0.4039 \\
\hline \multirow[t]{3}{*}{$\mathrm{Al}_{60}$ Glass $_{40}$} & 38.606 & 2.330 & 111 & 0.4036 \\
\hline & 44.855 & 2.019 & 200 & 0.4038 \\
\hline & 65.199 & 1.430 & 220 & 0.4045 \\
\hline
\end{tabular}

Table 3.1: Structural parameters of the composite samples with particle size $25 \mu \mathrm{m}$

\begin{tabular}{|c|c|c|c|c|c|c|c|c|c|}
\hline \multirow{2}{*}{ Samples } & \multicolumn{3}{|c|}{ Peakl } & \multicolumn{3}{|c|}{ Peak2 } & \multicolumn{3}{|c|}{ Peak3 } \\
\hline & WMMH & $2 \alpha$ & $\begin{array}{l}\text { Size of } \\
\text { crystals (nm) }\end{array}$ & WMMH & $2 \alpha$ & $\begin{array}{c}\text { Size } \begin{array}{c}\text { of } \\
\text { crystals }(\mathrm{nm})\end{array}\end{array}$ & WMMH & $2 \alpha$ & $\begin{array}{l}\text { Size of } \\
\text { crystals (nm) }\end{array}$ \\
\hline \multirow{3}{*}{$\mathbf{A l}_{20}$ Glass $_{80}$} & 0.15 & 38.60 & 1.088 & 0.15 & 44.85 & 1.111 & 0.10 & 65.20 & 1.829 \\
\hline & 0.27 & 38.64 & 0.605 & 0.27 & 44.89 & 0.617 & 0.18 & 65.23 & 1.016 \\
\hline & 0.03 & 38.56 & 5.440 & 0.03 & 44.80 & 5.654 & 0.02 & 65.18 & 9.143 \\
\hline \multirow{3}{*}{$\mathbf{A l}_{30}$ Glass $_{70}$} & 0.15 & 38.55 & 1.088 & 0.05 & 44.80 & 3.330 & 0.10 & 65.15 & 1.828 \\
\hline & 0.27 & 38.60 & 0.605 & 0.09 & 44.81 & 1.852 & 0.18 & 65.18 & 1.016 \\
\hline & 0.03 & 38.50 & 5.439 & 0.01 & 44.78 & 16.66 & 0.02 & 65.13 & 9.140 \\
\hline \multirow[b]{3}{*}{$\mathrm{Al}_{40}$ Glass $_{60}$} & 0.10 & 38.70 & 1.633 & 0.15 & 44.95 & 1.111 & 0.20 & 65.25 & 0.915 \\
\hline & 0.18 & 38.70 & 0.907 & 0.27 & 44.99 & 0.618 & 0.36 & 65.30 & 0.508 \\
\hline & 0.02 & 38.65 & 8.163 & 0.03 & 44.91 & 5.560 & 0.04 & 65.20 & 4.572 \\
\hline \multirow[b]{3}{*}{$\mathbf{A l}_{60}$ Glass $_{40}$} & 0.15 & 38.60 & 1.088 & 0.10 & 44.85 & 1.667 & 0.10 & 65.20 & 1.829 \\
\hline & 0.27 & 38.65 & 0.605 & 0.18 & 44.88 & 0.926 & 0.18 & 65.23 & 1.016 \\
\hline & 0.03 & 38.55 & 5.440 & 0.02 & 44.83 & 8.332 & 0.02 & 65.18 & 9.142 \\
\hline
\end{tabular}

Table 3.2: Solid state properties of composites samples with $25 \mu \mathrm{m}$ particle size

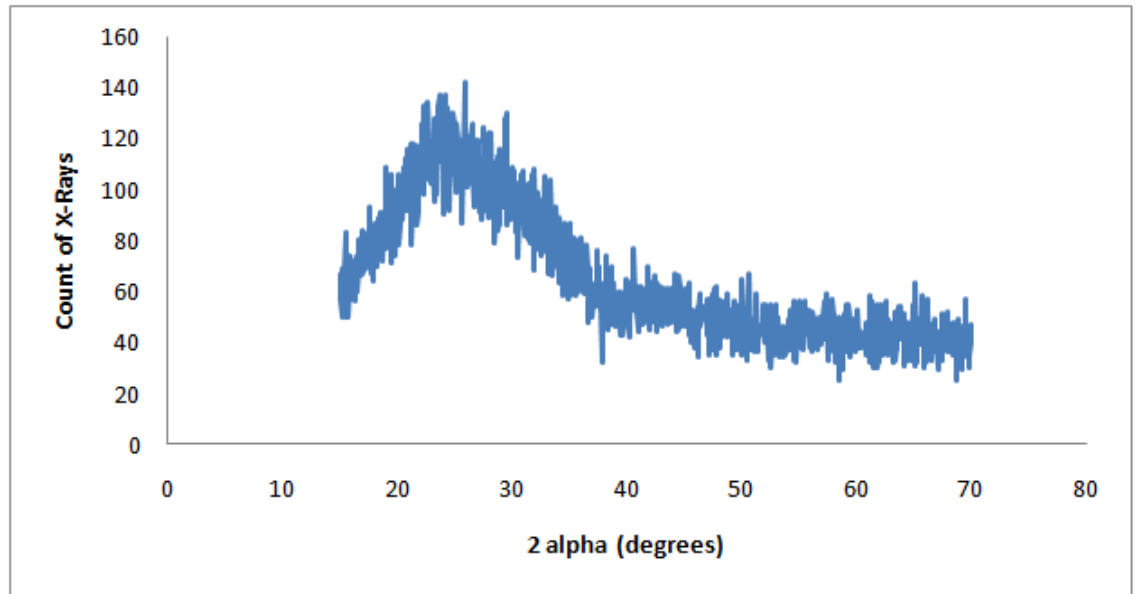

Fig. 3.1: X-ray diffraction of $\mathrm{Al}_{0} \mathrm{Glass}_{100}$ for $25 \mu \mathrm{m}$ particle size 


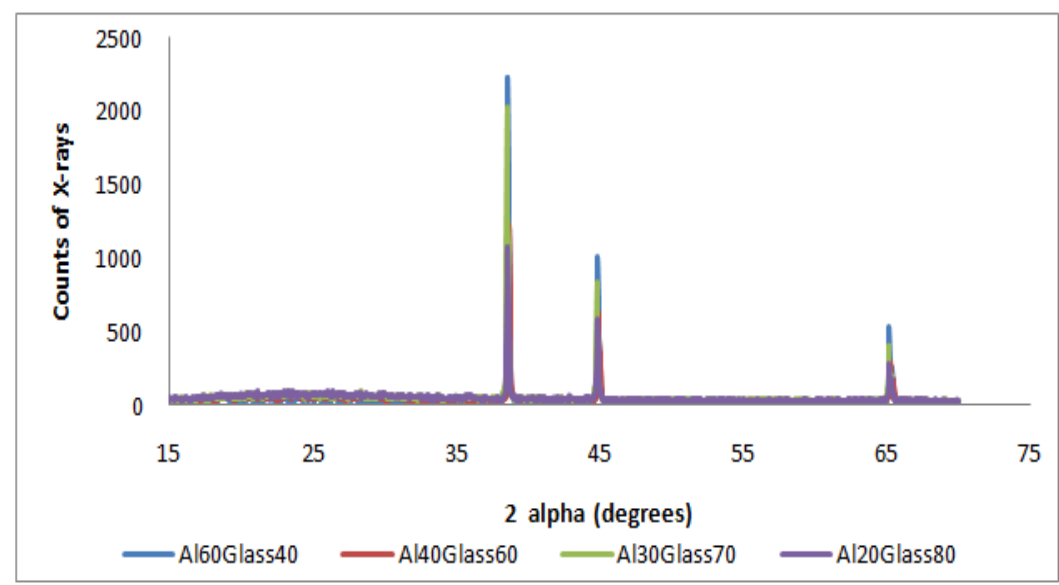

Fig. 3.2: X-ray diffraction of samples for $25 \mu \mathrm{m}$ particle size

\section{Discussion \\ Structural and Solid State Properties of Al-Glass Composites}

Tables 3.1- 3.2 show the structural parameters, solid state properties of the composites samples with particle size of $25 \mu \mathrm{m}$. Figure 3.1depicts the X-ray diffraction of sample $\mathrm{Al}_{0} \mathrm{Glass}_{100}$ with pronounced peak observed at $25.52^{\circ}$. The broad band as observed in the Figure 3.1 is as a result of the amorphous nature of Glass and probable micro strain. The X-ray diffraction pattern revealed variation in size of crystals of the Al-Glass composites as the weight of Aluminum increases in the samples. The distinct peaks and solid state properties showed that the materials are crystalline with increased Aluminum composition. The nature of each of the composites had three distinct crystal orientations i.e 111, 200 and 220 which reveal the Face Centered Cubic (FCC) and Body Centered Cubic (BCC) structures. The composites were also found to possess atomic nano sizes. Figure 3.2 shows the X-ray diffraction of $\mathrm{Al}_{20} \mathrm{Glass}_{80} \mathrm{Al}_{30} \mathrm{Glass}_{70}, \mathrm{Al}_{40} \mathrm{Glass}_{60}$, and $\mathrm{Al}_{60} \mathrm{Glass}_{40}$. Three distinct peaks of various heights for each sample were observed at $38.5^{\circ}, 44.78^{\circ}$ and $65.18^{\circ}$ respectively. The results reveal that as the composition of Aluminum increases, the peak counts increased. This increase in the count of X-rays is in order of 900 for 20-30 percent weight of Aluminum in composites which subsequently decrease with order of 800 for 30-40 percent weight Aluminum and systematically increase with order of 1000 for 40-60 percent weight of Aluminum in the composites. In addition, the composite materials were found to crystallize in Face Centered Cubic (FCC) and Body Centered Cubic (BCC) structures. As FCC material the composites can find applications in cryogenic dewars and buffer layers. The study agrees with previous research by $9 \& 10$.

\section{Conclusion}

Glassy materials are known to be brittle in nature; however, they have been noted to be very useful and applicable in day to day activities. These applications include; eye Glasses, homes / domestic decorations, laboratory hardware, building projects and in green house for plant development. Aluminum on the other hand, is a strong metal and useful in many areas such as building project, sliding window frame, door frames and roofing sheets etc. The combination of $\mathrm{Al}$ with other metal had been noted to generate improve performance in various device applications and utilization. Therefore, the structural properties of Glass could be adjusted for suitable application and utilization with appropriate reinforcement of $\mathrm{Al}$ in Glass. In the study, Al-Glass materials were prepared while structural stability was observed at nano particle size. The essence of the research is important as the material could be useful in modifying the properties of glazy materials. The material could also be useful for advanced nano devices. Having examined non hazardous nature of the material it is suggested that Al-Glass be used as pharmaceutical packaging material.

\section{References}

[1]. Guz, A.N. and Babich, Y.U. (2002) Stability of Composite Structural Members (Three-Dimensional Formulation), Journal of International Applied Mechanics, 38(9), 1048-1075.

[2]. Wu, J. M. and Li, Z. Z. (2000).Nanostructure Composite obtained by Mechanically Driven Reduction Reactions of $\mathrm{CuO}$ and Aluminum Powder Mixture, Journal of Alloys and Compound, 299, 9-16.

[3]. Simchi, A. and Reihani, S. M. Hesabi, Z. R. (2006). Structural Evolution during Mechanical Milling of Nanometric and Micrometric $\mathrm{Al}_{2} \mathrm{O}_{3}$ Reinforced Aluminum Matrix composites, Journal of Material Science Engineering, 428, 159-168.

[4]. Mahmoud, A. E., Abdalla, G. A, Wasly, H. S., Doheim, M. A., Aboraia, M. S. (2013). Characterization of $\mathrm{Al}^{-} \mathrm{Al}_{2} \mathrm{O}_{3}-\mathrm{ZrO}_{2}$ NanoComposite Powders Fabricated by High Energy Ball Milling, International Journal of Engineering Resource and Application, $3(3), 474-482$.

[5]. Yoldas, B. E. (1975). Monolithic Glass Formation by Chemical Polymerization, Journal of Material Science, 10, 1856. 
[6]. Victor, C. L., Michael, D. S., William, F. H. Ravi, R., and Todd, S. R. (2013). Composite Properties of High-Strength, HighDuctility Concrete, Advance Ceramic International Materials Journal, 110, 413-422.

[7]. David, R. E. and Einstein, T. L. (1993). Simple formula for Miller Indices of Periodically Kinked and Stepped FCC Surface, Journal of Surface Letters, 286 (1-2), 559-563.

[8]. Kasparan, J., Wolf, J. P., Ettoumi, W. and Petit, Y., (2010). General Miller Indices Formulae, Journal of Physics Optics, 1, 1-12.

[9]. 9. Hake, A.R., Dhokey, N. B., Batheja, R., Gite, R. and Thavale V. T. (2014) Microstructural and Mechanical Properties of Cryotreated SAE8620 and D3 Steels, Journal of Industrial Material Powder, 1 (1), 23-37.

[10]. Hisataka, H., Akihiro, M., Keisuke, S. and Wenchang, Y. (2014). Sputter Epitaxial Growth of Flat Germanium Film with Low Threading Dislocation Density on Silicon (001), Journal of Solid State Science and Technology, 113, 79- 85. 